\title{
An Analytical Model for Rotation Stiffness and Deformation of an Antiloosening Nut under Locking Force
}

\author{
X. J. Jiang, ${ }^{1}$ J. Hong, ${ }^{2}$ G. Q. Shao, ${ }^{2}$ L. B. Zhu, ${ }^{2}$ and Y. S. Zhu ${ }^{3}$ \\ ${ }^{1}$ The 16th Institute of the Ninth Academy, China Aerospace Science and Technology Corporation, Xian 710100, China \\ ${ }^{2}$ State Key Laboratory for Manufacturing System, Xian Jiaotong University, Xian 710049, China \\ ${ }^{3}$ Key Laboratory of Education Ministry for Modern Design and Rotor-Bearing System, Xian Jiaotong University, Xi'an 710049, China
}

Correspondence should be addressed to J. Hong; jhong@mail.xjtu.edu.cn

Received 2 May 2014; Accepted 2 July 2014; Published 29 September 2014

Academic Editor: Sergio Preidikman

Copyright (@) 2014 X. J. Jiang et al. This is an open access article distributed under the Creative Commons Attribution License, which permits unrestricted use, distribution, and reproduction in any medium, provided the original work is properly cited.

\begin{abstract}
Screw fasteners are undoubtedly one of the most important machine elements due to their outstanding characteristic to provide a high clamping force just with a simplified design. However, the loosen vibration is their inherent and inevitable fault. The friction locking approach is one of the basic locking fastener categories by enhancing the bearing load on the contact surface of thread by applying a locking force on an antiloosening nut. This locking force may cause more severe deformation in the nut. The contact stress distribution on the nut would be changed and that can cause the variation of the friction torque for the bolt joint. However, there exists no established design calculation procedure that accounts for the rotation deformation and its stiffness of the antiloosening nut under the locking force. The main objective of the work is to develop an analytical solution to the rotation deformation problem encountered in the antiloosening nut. The proposed model is supported by comparison with numerical finite element analysis of different sizes of joint elements and different applied forces.
\end{abstract}

\section{Introduction}

Screw fasteners are undoubtedly one of the most important machine elements. Their design simplicity to provide a high clamping force is the outstanding feature of screw fasteners. However, they have an inherent and inevitable fault: they all loosen eventually by vibration [1-3].

Some researches intended to make clear of the phenomenon of self-loosening of bolt based on the vibration theory [4-9]. However, the popularly known antiloosening fasteners do not seem to possess much resistance to loosening by the test results $[10,11]$ for the effectiveness of screw threads, spring washers, nylon inserted nuts, double nuts, and eccentric nuts of few sizes to resist loosening. Sase et al. [11] in the year 1998 introduced and evaluated the step lock bolt (SLB) with regard to its antiloosening performance using a displacement based loosening device. They found the presence of desirable antiloosening characteristics of SLB.

The friction locking approach is one of three basic locking fastener categories established by major companies [12, 13]. The mechanism of friction locking is to enhance the friction force by increasing the bearing load or the friction coefficients of contact surfaces of nut or bolt head and thread. One of the methods to enhance the friction force is to increase the bearing load of the contact surface of thread by applying one force on the nut in outside direction perpendicular to the bearing surface of nut. However, the bearing force and the bending deformation of nut will be influenced by this applied force. The bending deformation of the nut is determined by its bending rigidity that may never be discussed by other researches. In the present study, an analytical model was proposed to evaluate the bending rigidity of the nut under preload. The effects of the different forces produced by the small screw and applied on the nut were investigated on the bearing force and the bending deformation of the nut. The theoretical calculation procedure that considers this effect is presented in detail hereafter.

\section{Analytical Model}

The three basic elements that form an antiloosening nut discussed in present research are the upper nut, the lower 


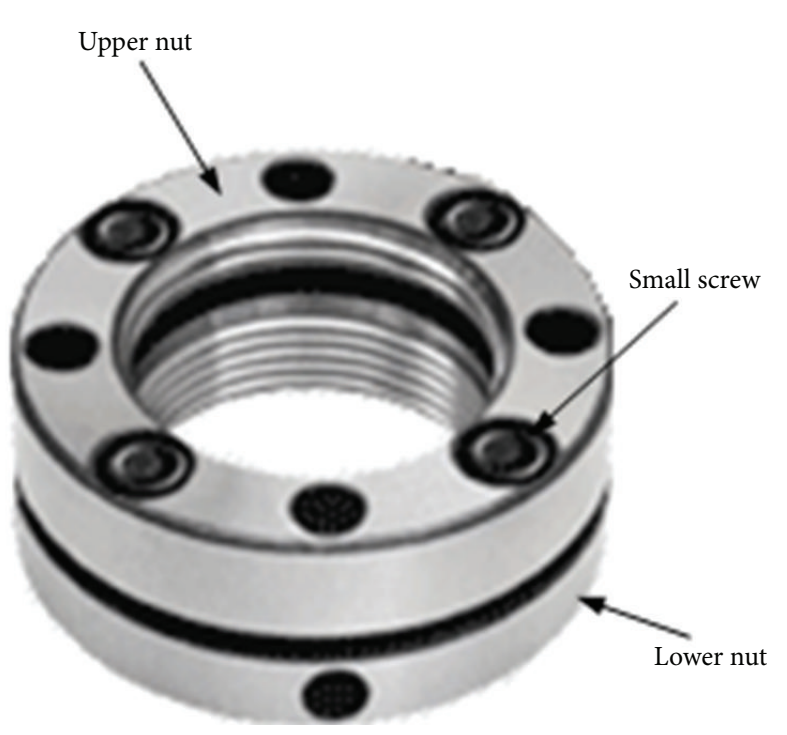

(a) Overall view picture

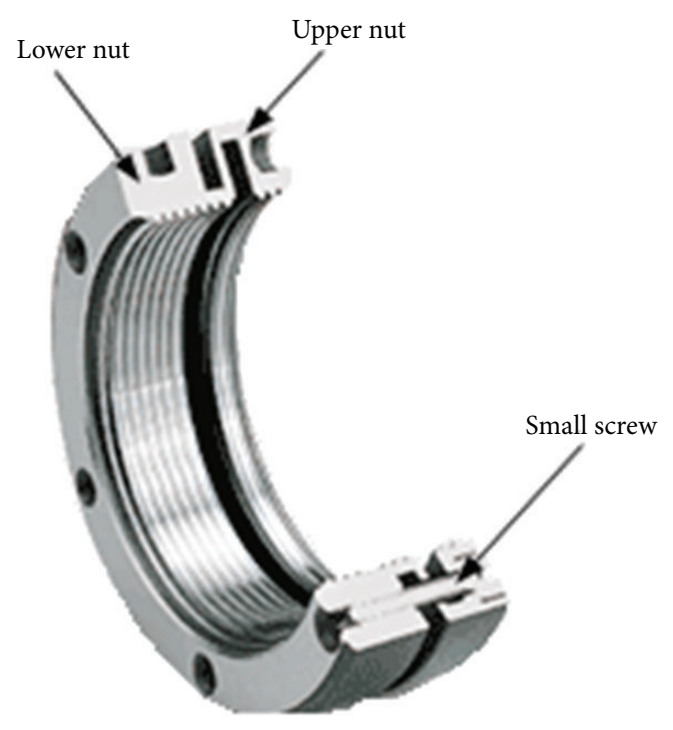

(b) Section view picture

Figure 1: Picture of an antiloosening nut.

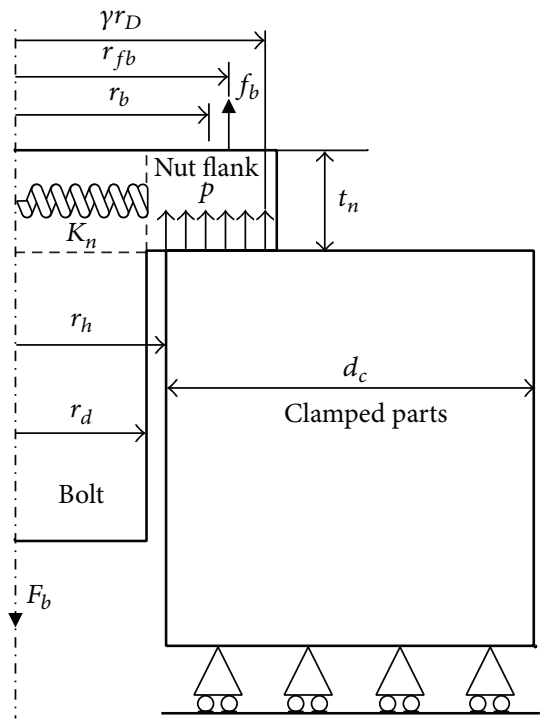

Figure 2: Bolted joint model under locking force.

nut, and the small screw, as shown in Figure 1. The lower nut is supported by clamped parts. The small screw is passed through the bolt hole in the upper nut. As the small screw is tightened, the extra large bearing force will be applied on the contact surface of nut threads that can enhance the antiloosening ability of bolted joint. Therefore, the tightening force produced by the small screw can be considered a locking force on the antiloosening nut.

The model used to simulate the joint with the antiloosening nut is shown in Figure 2. For the case involving clamped parts, bolt and nut are included. As with bolt force $F_{b}$, when a locking force $f_{b}$ is applied to the small screw, different

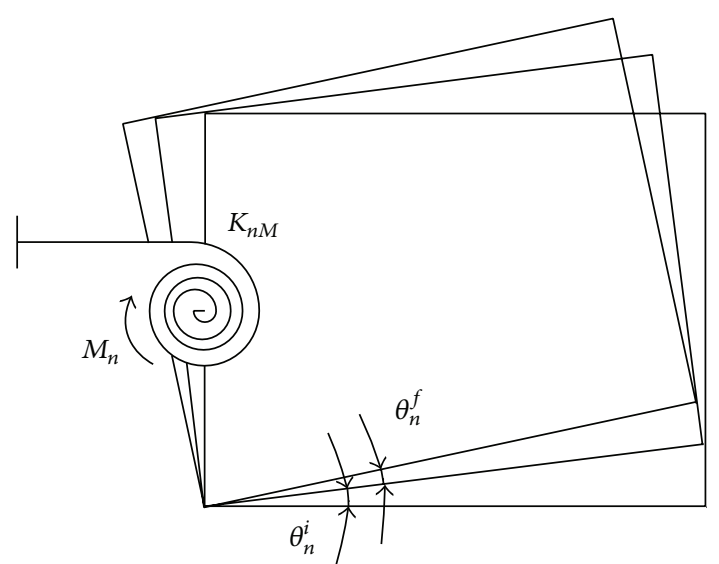

FIGURE 3: Nut flank rotation analysis.

rotation displacements and distortions at the nut flank are generated for the abovementioned joint components.

Before conducting the elastic interaction analyses, it is worth noting that the theoretical reference should be used to treat the different joint elements.

(1) The nut flank rotation is treated using the theory of beam on an elastic foundation without nonlinear distortion (Figure 3). The rotation angle of the nut flank is considered to be the rotation angle in the point of effective bearing friction radius $r_{b}$ of the nut bearing surface.

(2) The bolt part connected to the nut is represented by a compression spring of linear elastic stiffness $k_{n}$. The connected point of the spring to the nut is at the center point of the height $t_{n}$ of the nut. 
(3) The connected point of bolt and nut is simplified without the threads.

The elastic spring $K_{n}$ is given by

$$
K_{n}=\frac{E t_{n}}{r_{d}}
$$

where $r_{d}$ is the radius of the bolt axis, $t_{n}$ is the height of the nut, and $E$ is Young's modulus.

The rotational stiffness of the nut flank, which is formed by the nut flank and the connected part of bolt to the nut, is characterized by two parameters $k_{n M}$ and $k_{b f}$ depending on the dimensions of the joint elements. $k_{b f}$ is the bending rigidity of the nut flank due to a bending moment produced by the nut bearing load and can be calculated by the beam theory. $k_{n M}$ is the rotation rigidity due to the bending moment effect produced by the nut bearing load on the connected part of bolt to the nut. The expression of the rigidity $K_{b f}$ is

$$
K_{b f}=\frac{2 E I_{n}}{r_{b}-r_{d}},
$$

where $r_{b}$ is the effective bearing friction radius. $I_{n}$ is moment of inertia. $K_{n M}$ can be equivalently replaced by the compression rigidity of $K_{n}$ as follows:

$$
K_{n M}=K_{n}\left(\frac{t_{n}}{2}\right)^{2}=\frac{E t_{n}^{3}}{4 r_{d}} .
$$

Therefore, the rotational stiffness of the nut flank can be written as

$$
K=\frac{K_{n M} K_{b f}}{K_{n M}+K_{b f}}=\frac{E t_{n}^{3}}{6 r_{b}-2 r_{d}},
$$

where $r_{b}$ can be calculated by

$$
r_{b}=\frac{\int_{r_{d}}^{r_{o}} p r d r}{\int_{r_{d}}^{r_{o}} p d r} \approx \frac{\int_{r_{d}}^{r_{o}} p r^{2} d r}{\int_{r_{d}}^{r_{o}} p r d r}
$$

The equilibrium consideration in the joint is obtained for both the bolt initial preloading state $i$ and final small screw tightening state $f$, such that

$$
P_{n}^{i}=F_{b},
$$

and, from the small screw tightening equilibrium,

$$
P_{n}^{f}+f_{b}=F_{b}
$$

where $P_{n}$ is the bearing force of nut.

The initial and final rotation deformations of the nut flank are given by the following equations:

$$
\begin{aligned}
\theta_{n}^{i}= & \frac{M_{n}^{i}}{K}=\frac{2 F_{b}\left(3 r_{b}^{2}-4 r_{b} r_{d}+r_{d}^{2}\right)}{E t_{n}^{3}}, \\
\theta_{n}^{f}= & \frac{M_{n}^{f}}{K} \\
= & \left(2 F_{b}\left(3 r_{b}^{2}-4 r_{b} r_{d}+r_{d}^{2}\right)\right. \\
& \left.+2 f_{b}\left(3 r_{f b} r_{b}-r_{f b} r_{d}-3 r_{b}^{2}+r_{b} r_{d}\right)\right) \times\left(E t_{n}^{3}\right)^{-1},
\end{aligned}
$$

where

$$
\begin{aligned}
M_{n}^{i} & =P_{n}^{i}\left(r_{b}-r_{d}\right), \\
M_{n}^{f} & =P_{n}^{f}\left(r_{b}-r_{d}\right)+f_{b}\left(r_{f b}-r_{d}\right) \\
& =P_{n}^{i}\left(r_{b}-r_{d}\right)+f_{b}\left(r_{f b}-r_{b}\right)
\end{aligned}
$$

in which $r_{f b}$ is the radius of the small screw loading point. It is worth noting that as $f_{b}=0, \theta_{n}^{i}=\theta_{n}^{f}$.

The effective bearing friction radius $r_{b}$ can be obtained from the calculation results from Nassar's theory [14]. In that research, four scenarios of underhead load distribution are discussed (i.e., uniform underhead load, linearly decreasing load, exponentially decreasing load, and sinusoidal underhead load). A uniform pressure distribution simulates the use of a strong steel bolt and nut to clamp onto a much weaker clamping surface, such as plastic surfaces or soft washers. Other pressure distributions considered would simulate contact stress concentration at the edge of the fastener hole or represent the zero pressure conditions at minimum or maximum radii of the contact area. Nassar's theoretical equations [14] can be listed below, where $r_{b-t}$ means the theoretical calculation result of $r_{b}$.

Uniform underhead load:

$$
r_{b-t}=\frac{0.656\left(\gamma^{2.9}-1\right) r_{d}}{\gamma^{1.9}-1}
$$

Linearly decreasing load:

$$
r_{b-t}=\frac{0.95 r_{d}\left(\gamma^{2}-1\right)}{\gamma^{1.9}-1}\left(\frac{6 \gamma^{3.9}-23.4 \gamma+17.4}{11.3 \gamma^{3}-33.93 \gamma+22.62}\right) .
$$

Exponentially decreasing load:

$$
r_{b-t}=\frac{0.95\left(\gamma^{2}-1\right) r_{d}^{0.1}}{\gamma^{1.9}-1}\left(\frac{\int_{r_{d}}^{\gamma r_{d}} \gamma^{1.9} e^{-a\left(r-r_{d}\right)} d r}{\int_{r_{d}}^{\gamma r_{d}} \gamma e^{-a\left(r-r_{d}\right)} d r}\right),
$$

where $a=\ln \left(p_{\max } / p_{\min }\right) / r_{d}(\gamma-1)$.

Sinusoidal underhead load:

$$
\begin{aligned}
r_{b-t}= & \frac{0.95\left(\gamma^{2}-1\right) r_{d}^{0.1}}{\gamma^{1.9}-1} \\
& \times\left(\frac{\int_{r_{d}}^{\gamma r_{d}} \gamma^{1.9} \sin \left[\pi\left(r-r_{d}\right) / r_{d}(\gamma-1)\right] d r}{\int_{r_{d}}^{\gamma r_{d}} \gamma \sin \left[\pi\left(r-r_{d}\right) / r_{d}(\gamma-1)\right] d r}\right),
\end{aligned}
$$

where $\gamma$ is the value of the maximum to minimum contact radii ratio.

\section{Numerical FE Model}

To validate the analytical model that estimates the rotation rigidity and deformation of the nut flank, a two-dimensional axisymmetric numerical FE model was constructed. A 2D 4node element PLANE42 with two degrees of freedom per 


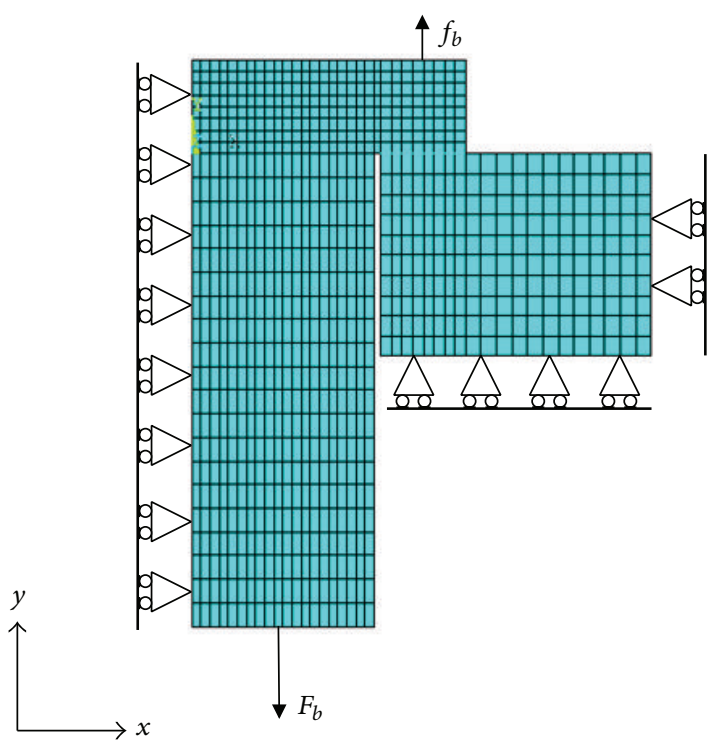

FIgURE 4: 2D finite element model.

node in ANSYS [15] was used to model the bolt joint, as shown in Figure 4. Young's modulus is $195 \mathrm{GPa}$ and Poisson's ratio is 0.3 . In the definition of contact pairs for finite element analysis, the contact surface of clamped part is assigned to be the target element TARGE169, and the contact surface of nut is the contact element CONTA172.

The antisymmetry DOF constraint along $x$-axis is applied on the bolt axis. The bottom of the clamped part is also restrained in displacement in $y$ direction. The right side of the clamped part is also restrained in displacement in $x$ direction. The loading is applied in two steps. The first step consists of applying an initial nut-up. This is achieved by imposing to the bolt end-plane nodes, an equivalent axial node force to produce the target initial bolt-up stress of $28.8 \mathrm{MPa}$. A locking force $f_{b}$ produced by the small screw that depends on the case studied is applied in the second step. Comparisons between the analytical method and finite element method results were conducted on different geometries of joint elements and different applied forces.

\section{Results and Discussion}

Figure 5 shows the result of the stress distribution along $y$ axis. The stress concentration can be found at the connecting corner of bolt and nut that produces the stress of about $260 \mathrm{MPa}$. The rotation of the nut flank can be observed obviously. The results of nut flank rotation after applied loads obtained from the proposed analytical approach are compared to those of FE model for the different applied loads and different sizes of joint elements.

Figure 6 shows the variation of the average values of the contact pressure of bolt and nut with the change of the locking force from the small screw. It can be seen that the average value decreases with the increase in the locking force. A difference between the analytical model and FEA that may be owing to the stress concentration at the detached point

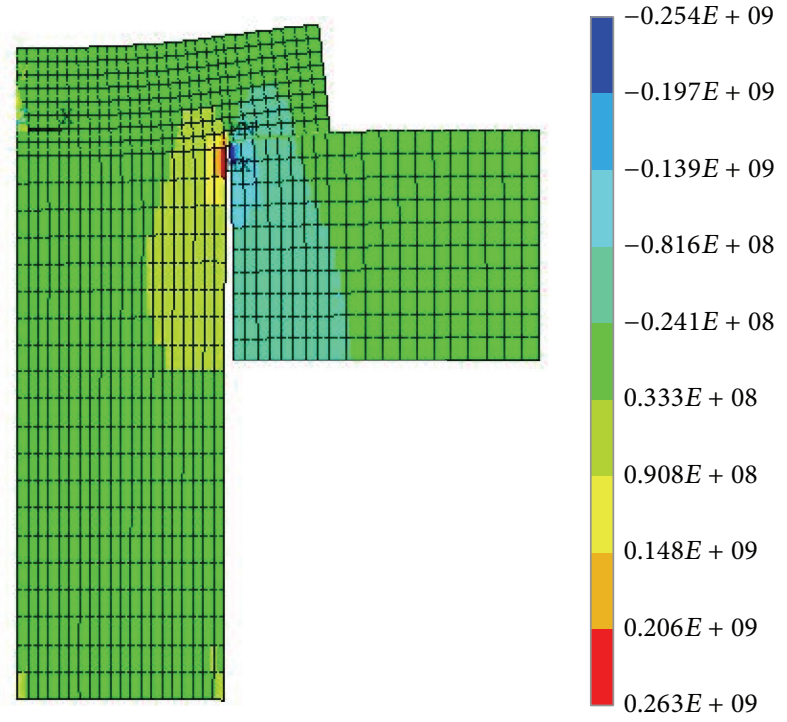

FIGURE 5: $y$-axis stress and deformation of joint under preload force.

of the contact area of the bolt and nut is also shown for two different bolt force cases. Figure 7 depicts the rotation deformation of the nut flank after the locking force is applied. From Figure 7, it can be found that the effective bearing friction radius $r_{b}$ obtained from the calculation results from Nassar's theory for different underhead load distribution cannot effectively calculate the rotation deformation of the nut flank for different bolt force $F_{b}$ besides the exponentially decreasing load case. The results given by the uniform distribution and the sinusoidal distribution are very close. On the other hand, the results given by the linear distribution and the exponentially decreasing distribution are also close. However, the exponentially decreasing distribution gives much better results than other distributions as $P_{\max } / P_{\min }=5$. Hereafter, the proportional coefficient $P_{\max } / P_{\min }=5$ for the exponentially decreasing load distribution is considered to calculate the rotation stiffness and deformation for the different sizes of joint elements at $F_{b}=200 \mathrm{kN}$ and $f_{b}=$ $3500 \mathrm{~N}$. It should be noted that $\gamma$ ratio is 1.4 for all cases.

Figure 8 shows the comparison of the results for the different $r_{D}$ case by the analytical model and FEA.

The analytical and FEA results are in a good agreement with a maximum difference of $0.9 \%$ between the two methods. The increase in $r_{D}$ will generate a smaller rotation stiffness of the nut flank according to (2), which contributes to a larger value of the rotation deformation of the nut flank. From Figure 9, a good agreement between this stiffness and these deformations for different clearance $d_{n}$ between the bolt and the clamped part is obtained. The decrease in the rotation stiffness $k$ as $d_{n}$ increase will be enhanced by (4). Therefore, as $F_{b}$ and $f_{b}$ are fixed, the bending moment $M_{n}^{f}$ can be shown to increase as $d_{h}$ increases, which leads to the glowing of the rotation deformation of the nut flank. The results of the calculated stiffness and deformations of the nut flank with the analytical model as shown in Figure 10 are in good agreement with those obtained by the FEM for the case 


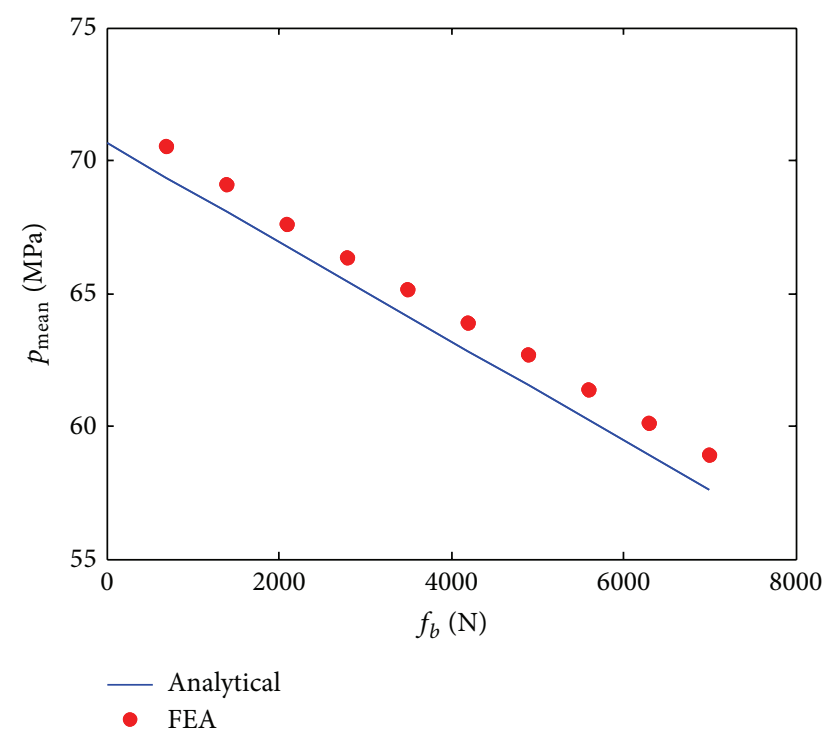

(a) $F_{b}=200 \mathrm{kN}$

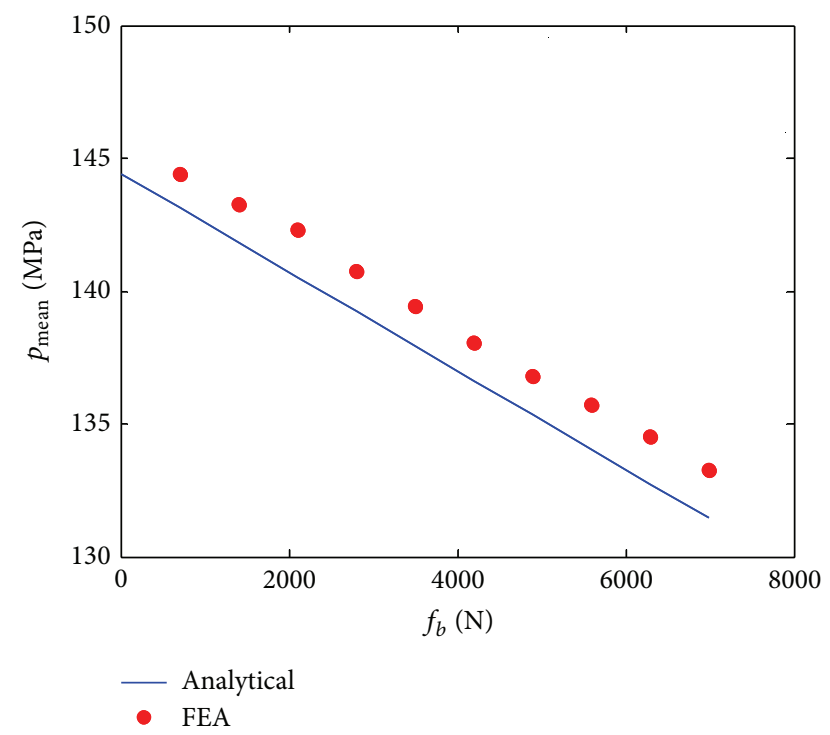

(b) $F_{b}=400 \mathrm{kN}$

Figure 6: Average value of the underhead contact pressure under different locking force.

of different height $t_{n}$ of the nut. The difference between the two methods is less than $20 \%$. The difference between the results is due to the linear simplification made on the nut flank mechanical behavior. According to (4), the increase in the height $t_{n}$ will raise the rotational stiffness of the nut flank. The rotation deformation will decrease in this case.

In order to analyze the effect of the role position of the locking force $f_{b}$, the different $r_{f b}$ case is discussed in this paper. Good agreement results for the different $r_{f b}$ case by the analytical model and by the FEA (Figure 11) are shown. In this case, the rotation stiffness will not be changed because of the same geometry size of the joint elements. The built-up of $r_{f b}$ will increase the bending moment $M_{h}^{f}$, so the rotation deformation is increased with the growth of $r_{f b}$.

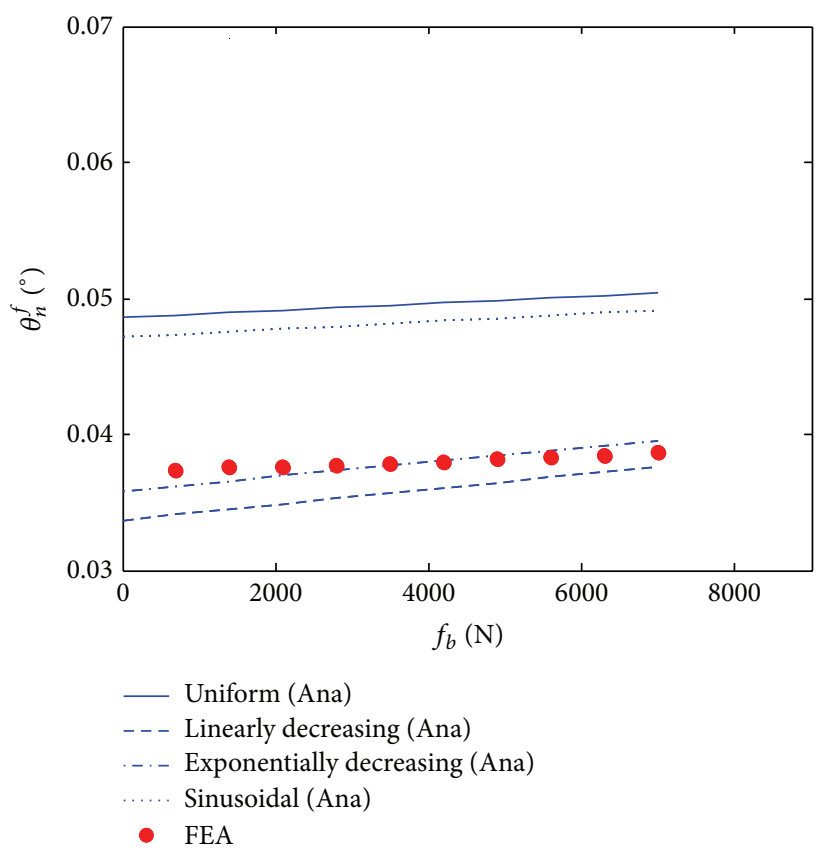

(a) $F_{b}=200 \mathrm{kN}$

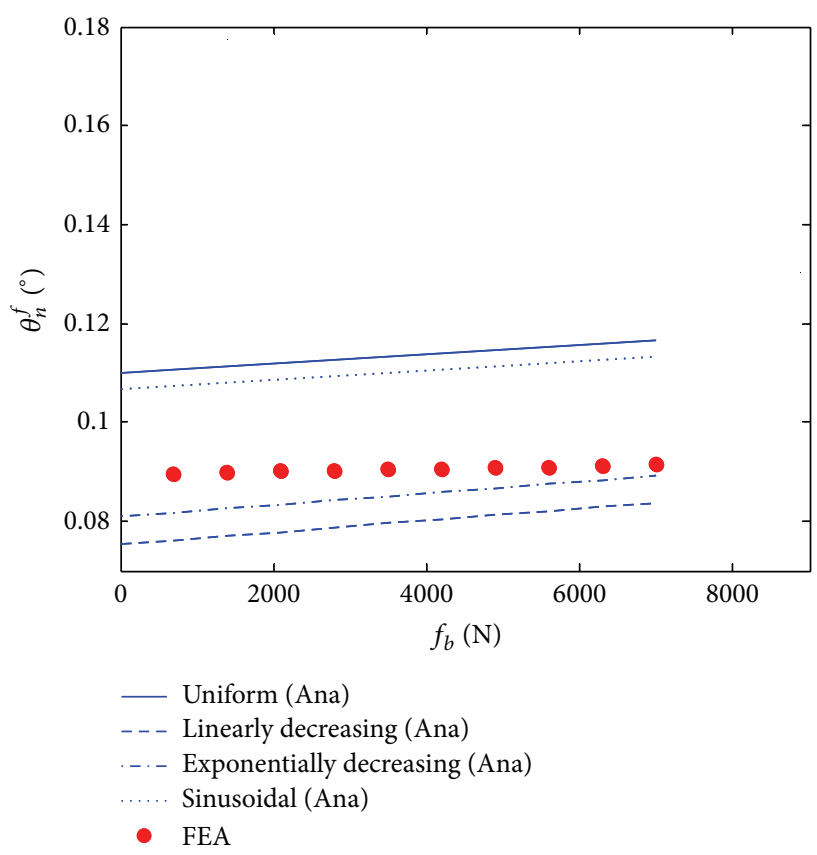

(b) $F_{b}=400 \mathrm{kN}$

FIGURE 7: Rotation deformation of nut flank.

\section{Conclusions}

An analytical method has been developed to analyze a bolt joint with an antiloosening nut. The developed model based on the beam theory has shown rationality solution in the rotation stiffness and deformations of the nut flank. The analyses are verified against the accurate 2D FEM on different sizes of joint elements and different applied forces. The analytical results of the rotation stiffness and deformations 


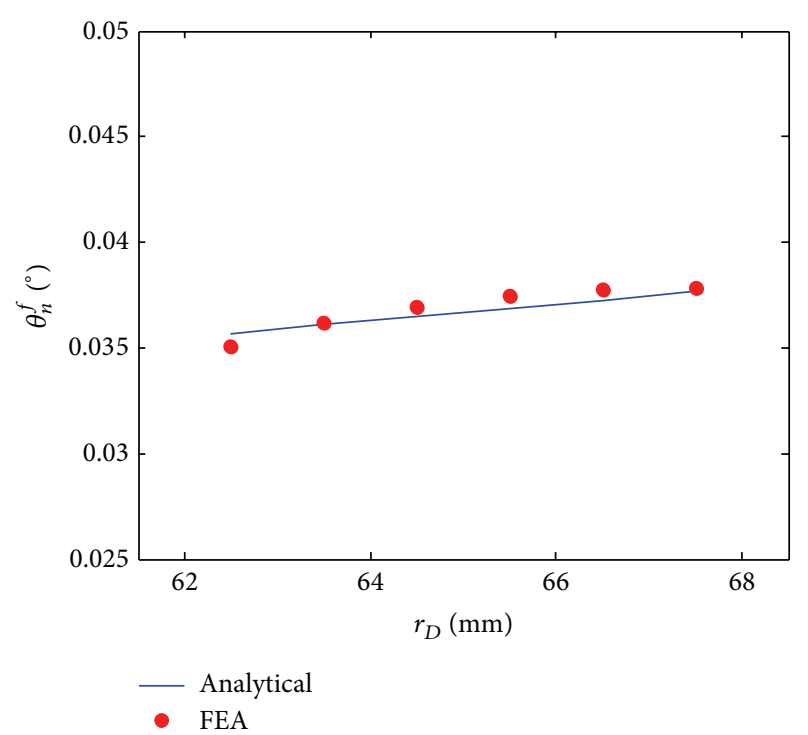

(a) Rotation deformation

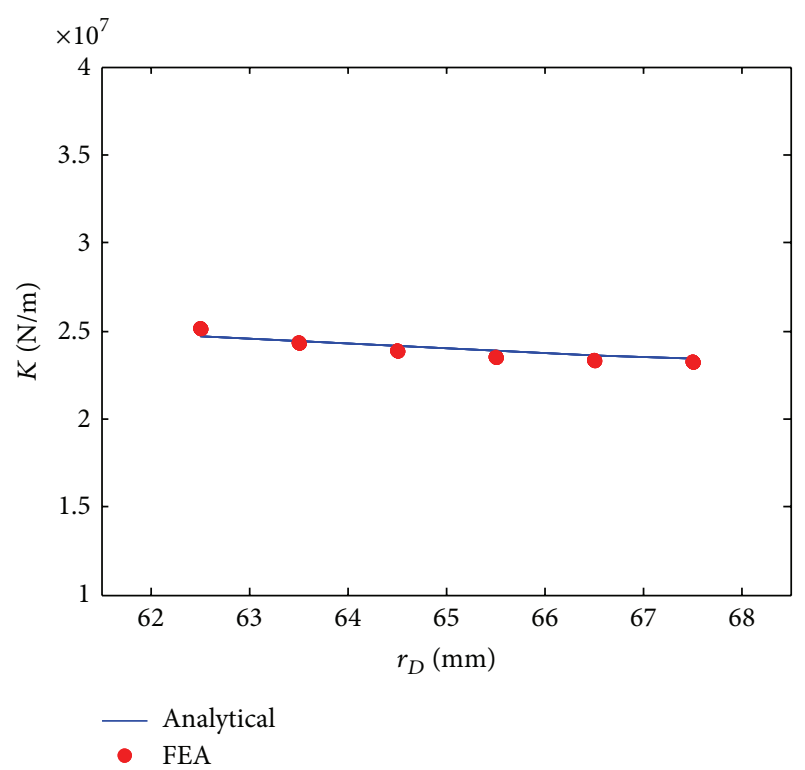

(b) Rotation stiffness

Figure 8: Rotation stiffness and deformation of nut flank with variation of $r_{D}$.

compare quite well with those of FEM. It is confident that the analytical model has the ability to predict the deformation and the contact load of the antiloosening nut.

\section{Nomenclature}

$d_{n}$ : Clearance between the bolt and the clamped part

$F_{b}$ : Bolt force

$f_{b}$ : Locking force

$E$ : Young's modulus

$I_{n}$ : Moment of inertia

$k_{b f}$ : Bending rigidity of the nut flank

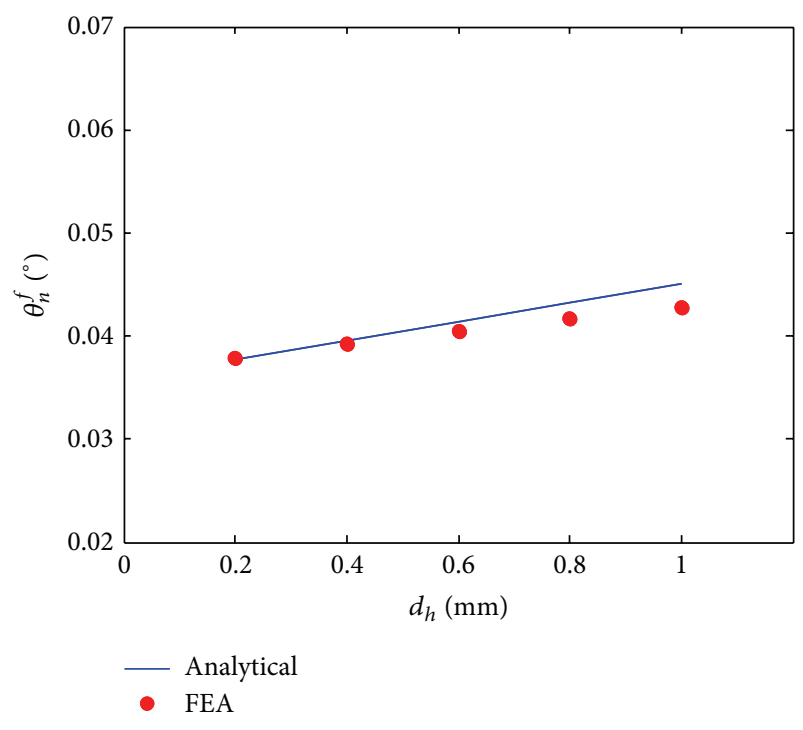

(a) Rotation deformation

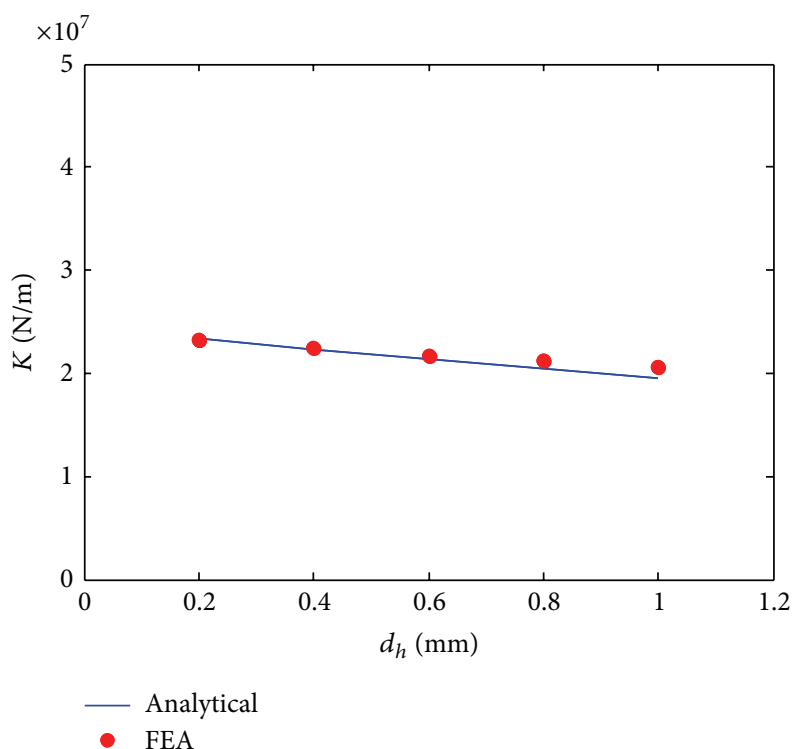

(b) Rotation stiffness

Figure 9: Rotation stiffness and deformation of nut flank with variation of $d_{n}$.

$k_{n}$ : Linear elastic stiffness of compression spring

$k_{n M}$ : Rotation rigidity due to the bending moment effect

$P_{n}$ : Bearing force of nut

$r_{b}$ : Effective bearing friction radius

$r_{b-t}$ : The theoretical calculation result of $r_{b}$

$r_{d}$ : Radius of the bolt

$r_{f b}$ : Radius of the small screw loading point

$t_{n}$ : Height of the nut

$\theta_{n}^{i}$ : Initial and final rotation deformations

$\theta_{n}^{f}$ : Final rotation deformations. 


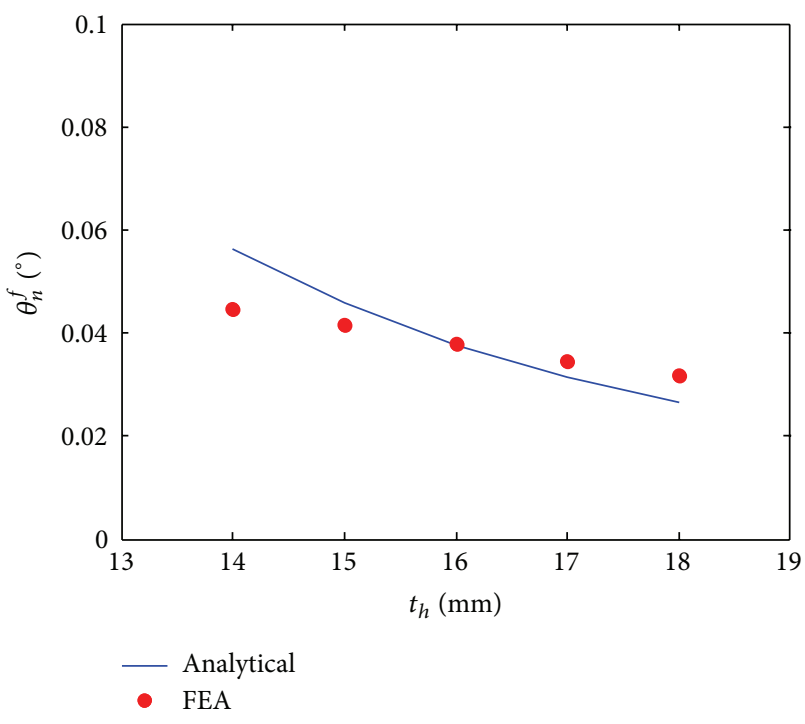

(a) Rotation deformation

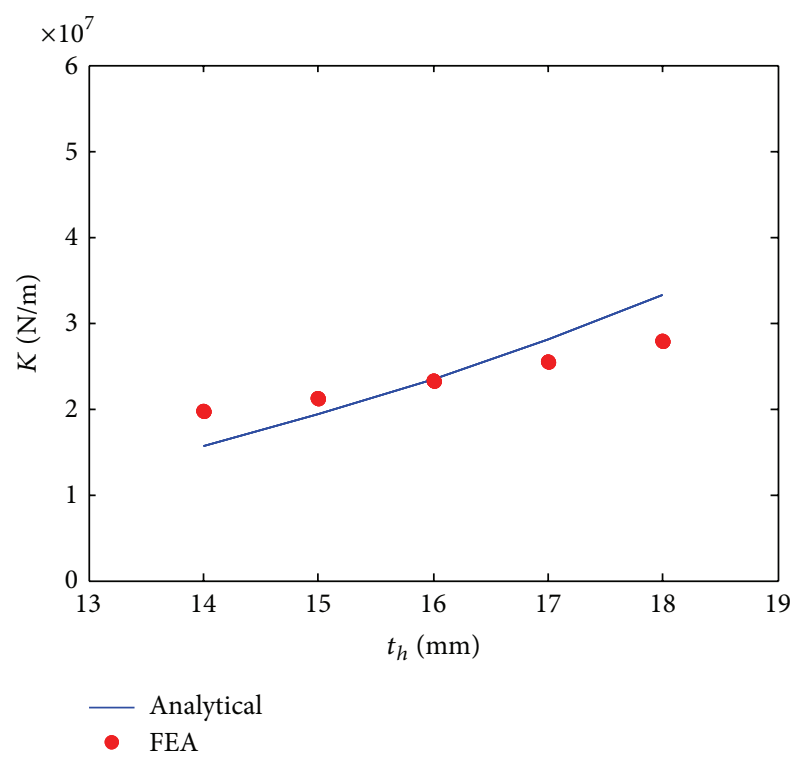

(b) Rotation stiffness

FIGURE 10: Rotation stiffness and deformation of nut flank under different locking force with variation of $t_{n}$.

\section{Conflict of Interests}

The authors declare that there is no conflict of interests regarding the publication of this paper.

\section{Acknowledgments}

The authors would like to express their thanks for the financial support of this work by the National High-tech R\&D Program of China (863 Program) under Grant no. 2012AA040701, the National Basic Research Program of China (Grant no. 2011CB706600), the National Natural Science Foundation of China (no. 51405371), and the National

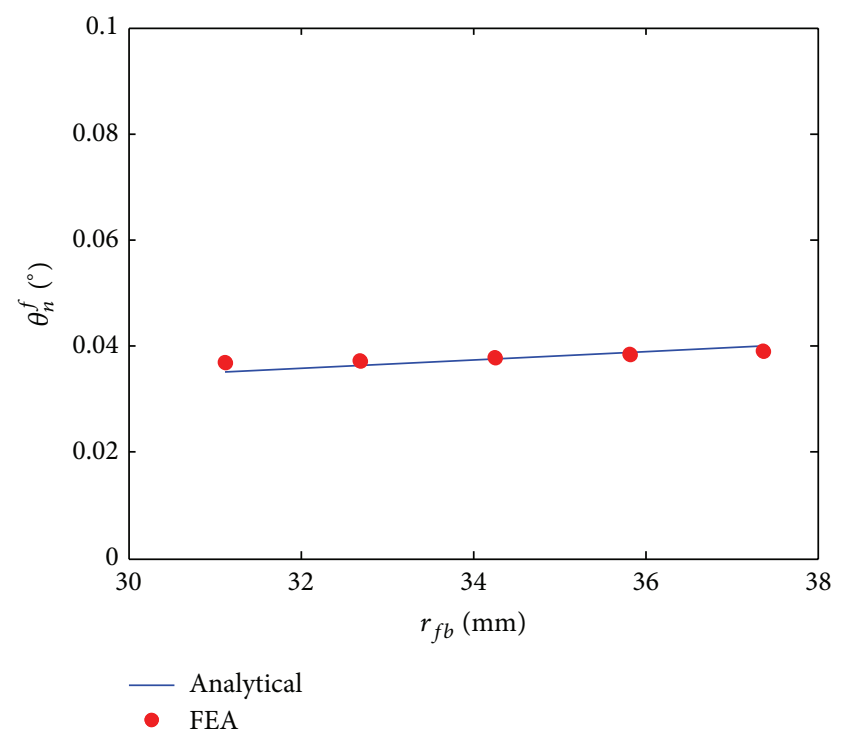

FIGURE 11: Rotation deformation of nut flank under different locking force with variation of $r_{f b}$.

Science and Technology MajorProject of China (no. 2012ZX04005-011).

\section{References}

[1] G. H. Junker, "New criteria for self-loosening of fasteners under vibration," SAE Technical Papers, vol. 78, pp. 314-335, 1969.

[2] A. Yamamoto and S. Kasei, "Investigations on the self-loosening of threaded fasteners under transverse vibration," Journal of the Japan Society of Precision Engineering, vol. 42, no. 6, pp. 507-511, 1976.

[3] N. Sase, S. Koga, K. Nishioka, and H. Fuji, "Evaluation of anti-loosening nuts for screw fasteners," in Proceedings of the International Conference on Advanced Materials Processing Technologies (AMPT '93), vol. 93, pp. 1051-1062, 1993.

[4] N. G. Pai and D. P. Hess, “Three-dimensional finite element analysis of threaded fastener loosening due to dynamic shear load," Engineering Failure Analysis, vol. 9, no. 4, pp. 383-402, 2002.

[5] N. G. Pai and D. P. Hess, "Experimental study of loosening of threaded fasteners due to dynamic shear loads," Journal of Sound and Vibration, vol. 253, no. 3, pp. 585-602, 2002.

[6] Y. Jiang, M. Zhang, T.-W. Park, and C.-H. Lee, "An experimental investigation on self-loosening of bolted joints," in Proceedings of the ASME Pressure Vessels and Piping Conference, pp. 20-24, Cleveland, Ohio, USA, July 2003.

[7] Y. Jiang, M. Zhang, and C. H. Lee, "Finite element modeling of self-loosening of bolted joints," ASME Journal of Mechanical Design, vol. 129, pp. 218-226, 2007.

[8] R. I. Zadoks and X. Yu, "Preliminary study of self-loosening in bolted connections," in Proceedings of the 14th Biennial Conference on Mechanical Vibration and Noise, pp. 79-88, September 1993.

[9] R. I. Zadoks and X. Yu, "An investigation of the self-loosening behavior of bolts under transverse vibration," Journal of Sound and Vibration, vol. 208, no. 2, pp. 189-209, 1997. 
[10] N. Sase, S. Koga, K. Nishioka, and H. Fujii, "Evaluation of anti-loosening nuts for screw fasteners," Journal of Materials Processing Technology, vol. 56, pp. 321-332, 1996.

[11] N. Sase, K. Nishioka, S. Koga, and H. Fujii, "An anti-loosening screw-fastener innovation and its evaluation," Journal of Materials Processing Technology, vol. 77, no. 3-4, pp. 209-215, 1998.

[12] A. Bhattacharya, A. Sen, and S. Das, "An investigation on the anti-loosening characteristics of threaded fasteners under vibratory conditions," Mechanism and Machine Theory, vol. 45, no. 8, pp. 1215-1225, 2010.

[13] H. Fuji and N. Sase, "SLB Concept for screw fastening and its anti-loosening performance, Souvenir," in Proceeding of the 18th All India Manufacturing Technology Design and Research Conference, pp. 21-23, 25-34, Kharagpur, India, December 1998.

[14] S. Nassar, G. C. Barber, and D. Zuo, "Bearing friction torque in bolted joints," in Proceedings of the 59th STLE Annual Meeting, pp. 17-20, Toronto, Canada, 2004.

[15] ANSYS 5.1, Swanson Analysis System, Inc., Houston, Pa, USA, 1995. 

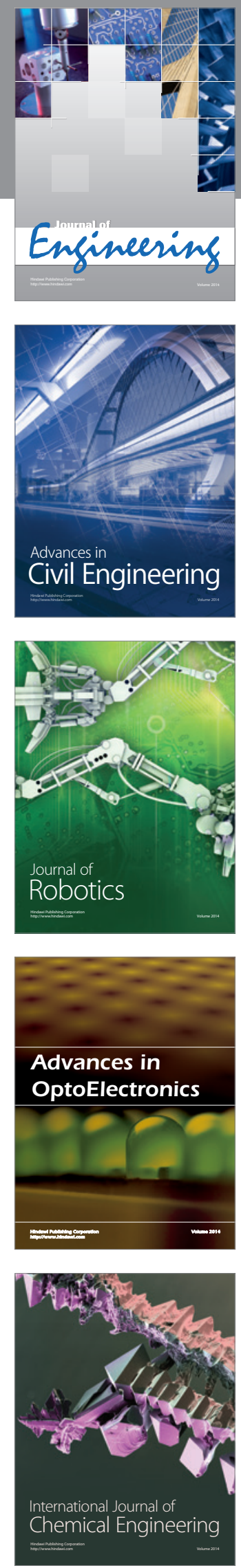

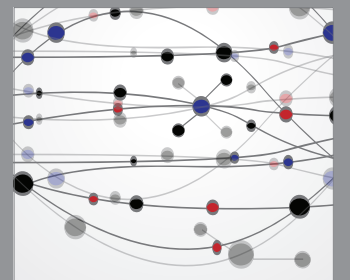

The Scientific World Journal
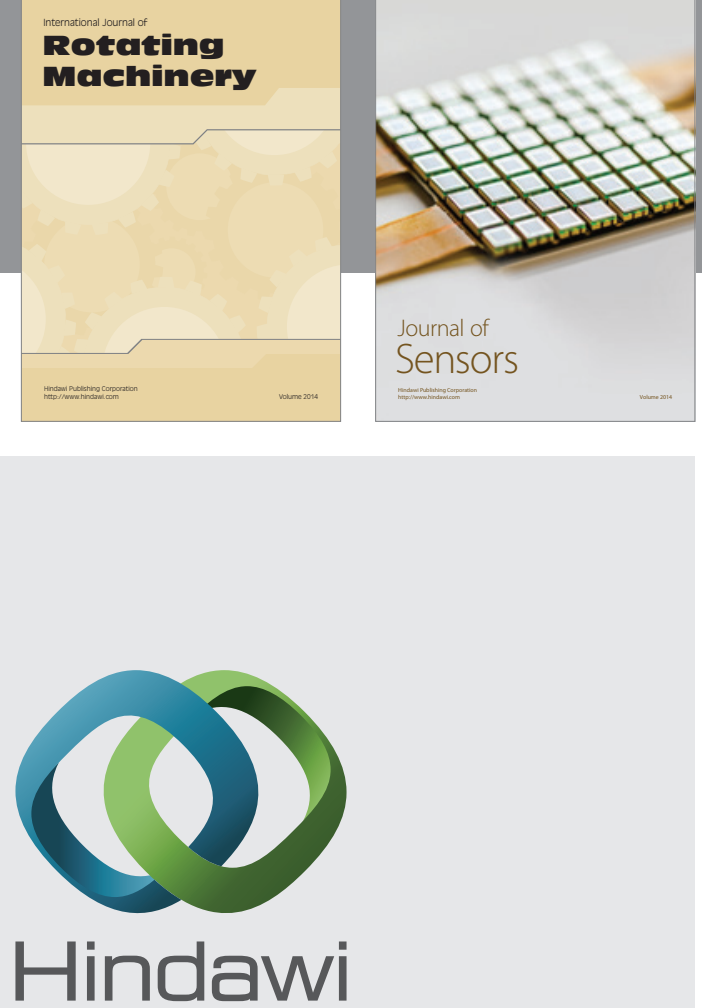

Submit your manuscripts at http://www.hindawi.com
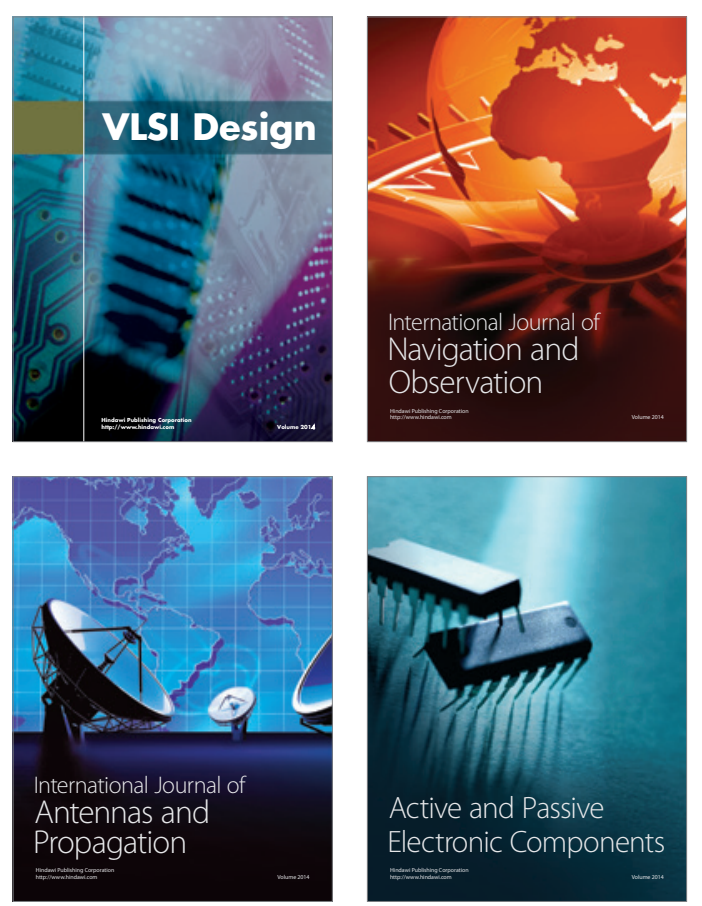
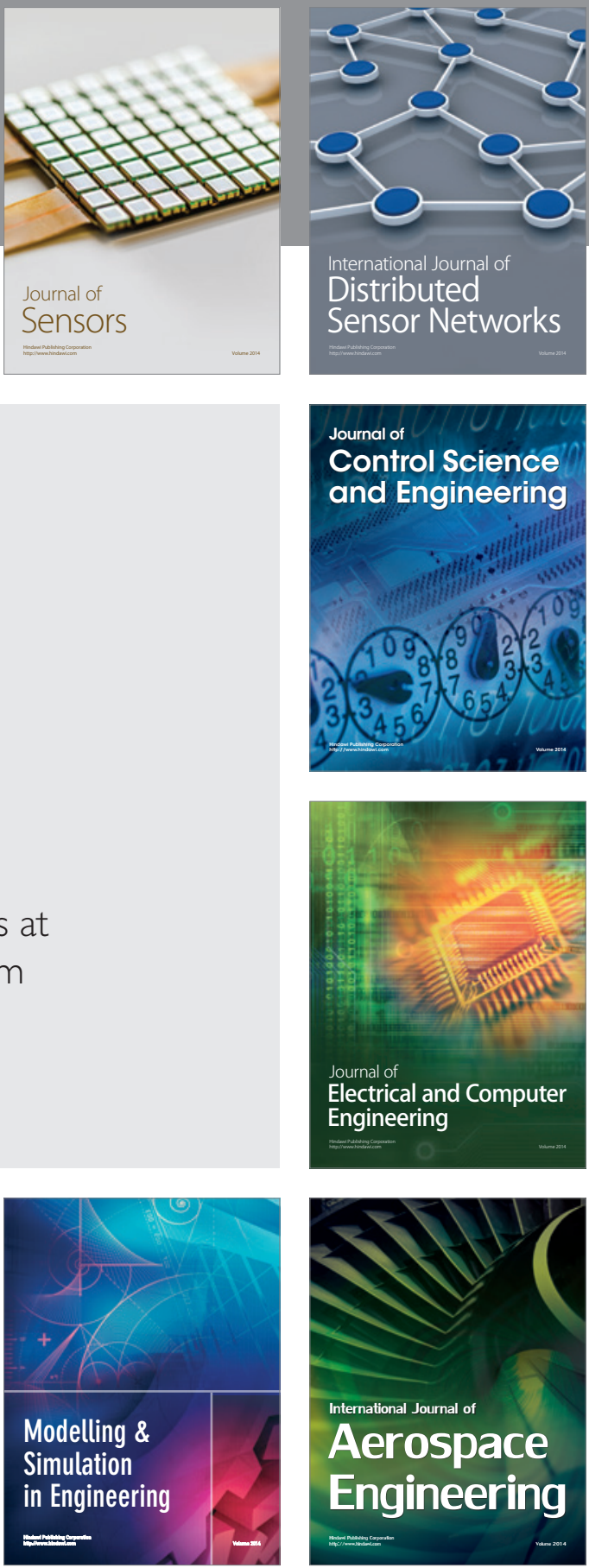

Journal of

Control Science

and Engineering
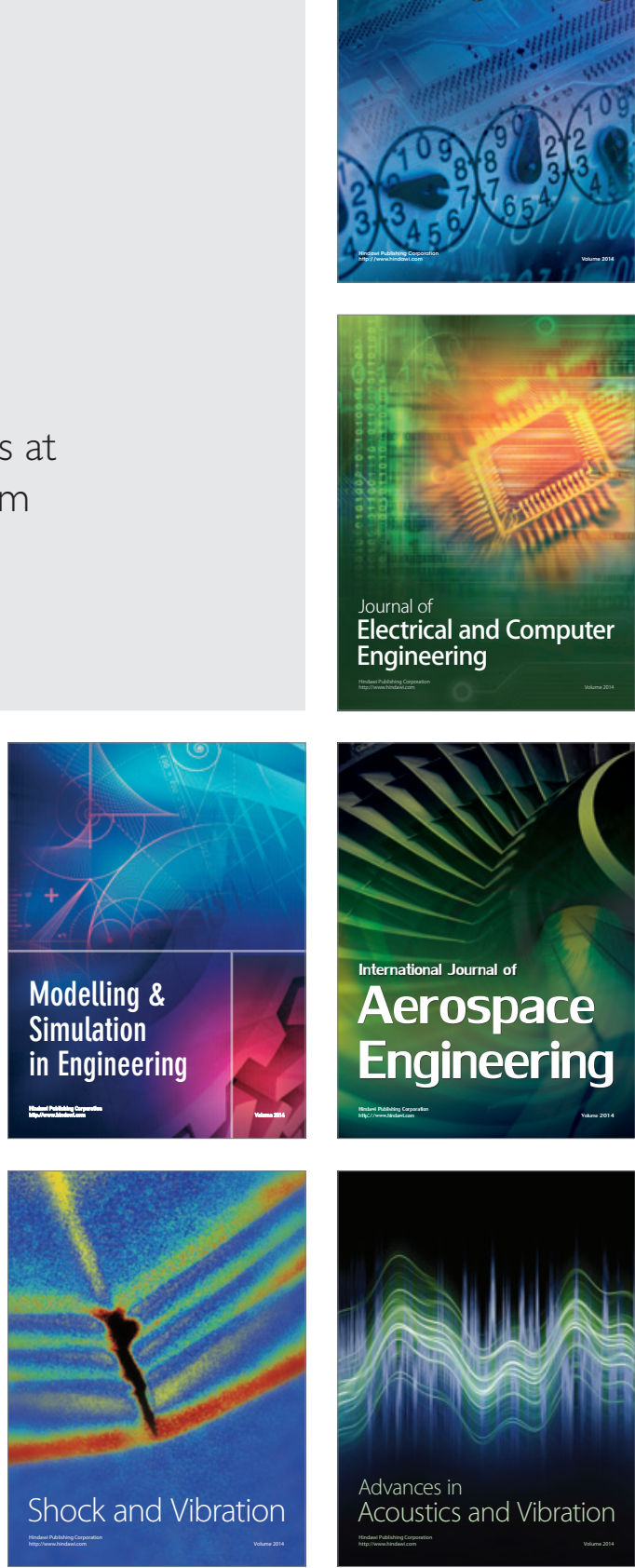